\title{
Correction
}

\section{CSF tau protein phosphorylated at threonine 231 correlates with cognitive decline in MCI subjects}

In the study "CSF tau protein phosphorylated at threonine 231 correlates with cognitive decline in MCI subjects" (Neurology 2002;59:627-629) by Buerger et al., the authors report a significant correlation between CSF p-tau ${ }_{231}$ levels at baseline and rate of annual point loss in MMSE score in the MCI group, both in the single effect analysis (Spearman's rho $=-0.30, p<0.01$ ) and after controlling for covariates in the multiple regression model (beta $=-0.23 ; p=0.049$ ). Because of an error in the data layout, the duration of the observation period was erroneous for one subject. When this error was corrected, the correlation between p-tau and point loss in MMSE score remained unchanged. However, the result pattern of the multiple regression model was partially changed: Older age at baseline (beta $=-0.33 ; p<0.01$ ) and APOE $\epsilon 4$ carrier stats (beta $=-0.40 ; p<0.01$ ) still were significant predictors of cognitive decline. P-tau ${ }_{231}$ remained in the model, but the beta weight was slightly reduced (beta $=-0.23$ before and -0.22 after correction) and the effect showed a tendency toward statistical significance ( $p=0.06$, instead of $p=0.049$ as previously published). The basic result of the study, however, remains unchanged, i.e., CSF p-tau ${ }_{231}$ levels at baseline correlate with rate of annual point loss in MMSE score in the MCI group. 


\section{Neurology}

\section{CSF tau protein phosphorylated at threonine 231 correlates with cognitive decline in MCI subjects}

Neurology 2004;63;1144

DOI 10.1212/WNL.63.6.1144

This information is current as of September 27, 2004

\section{Updated Information \&}

Services

Permissions \& Licensing

Reprints including high resolution figures, can be found at: http://n.neurology.org/content/63/6/1144.full

Information about reproducing this article in parts (figures,tables) or in its entirety can be found online at:

http://www.neurology.org/about/about_the_journal\#permissions

Information about ordering reprints can be found online:

http://n.neurology.org/subscribers/advertise

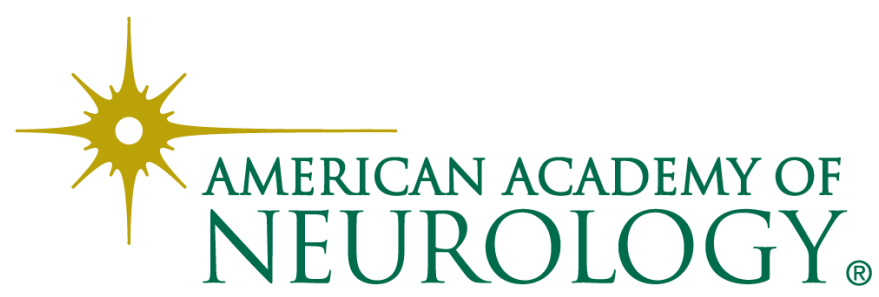

